Journal of Southeast Asian

\title{
Editors' Introduction - Fulfilling a Critical Need: The Journal of Southeast Asian American Education \& Advancement
}

\author{
Wayne E. Wright \\ University of Texas San Antonio, wewright@purdue.edu \\ KimOanh Nguyen-Lam \\ California State University, Kimoanh.Nguyen-Lam@ed.gov \\ Chhany Sak-Humphry \\ University of Hawaii at Manoa, sak@hawaii.edu \\ Leslie Turpin \\ School for International Training, Imturpin@sover.net \\ James Knaack \\ University of Texas, San Antonio, jamesknaack@yahoo.com
}

Follow this and additional works at: https://docs.lib.purdue.edu/jsaaea

Part of the Asian American Studies Commons, and the Education Commons

\section{Recommended Citation}

Wright, Wayne E.; Nguyen-Lam, KimOanh; Sak-Humphry, Chhany; Turpin, Leslie; and Knaack, James (2006) "Editors' Introduction - Fulfilling a Critical Need: The Journal of Southeast Asian American Education \& Advancement," Journal of Southeast Asian American Education and Advancement. Vol. 1 : Iss. 1, Article 1. DOI: $10.7771 / 2153-8999.1000$

Available at: https://docs.lib.purdue.edu/jsaaea/vol1/iss1/1

This document has been made available through Purdue e-Pubs, a service of the Purdue University Libraries. Please contact epubs@purdue.edu for additional information.

This is an Open Access journal. This means that it uses a funding model that does not charge readers or their institutions for access. Readers may freely read, download, copy, distribute, print, search, or link to the full texts of articles. This journal is covered under the CC BY-NC-ND license. 


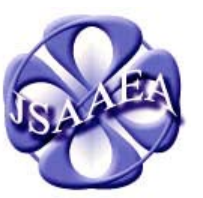

Volume 1
Journal of Southeast Asian American

\section{Education \& Advancement}

October 2006

http://jsaaea.coehd.utsa.edu/index.php/JSAAEA
A peer-reviewed

scholarly journal

published by the

National Association

for the Education \&

Advancement of

Cambodian, Laotian,

and Vietnamese

Americans (NAFEA)

\title{
Editors' Introduction
}

\section{Fulfilling a Critical Need: \\ The Journal of Southeast Asian American Education \& Advancement}

\begin{abstract}
Welcome to the Journal of Southeast Asian American Education \& Advancement (JSAAEA). This is the first scholarly peer-reviewed journal providing a forum for scholars and writers from diverse fields who share a common interest in Southeast Asian (SEA) Americans and communities.
\end{abstract}

\section{Southeast Asian Americans}

Although Southeast Asia is a larger area made of six countries, Southeast Asian Americans originated primarily from Cambodia, Laos, and Vietnam. They began to arrive in the United States in the mid-1970s as refugees when their countries fell into communism. Within a span of three decades, Southeast Asian Americans have drastically changed the demographics of public schools, especially in areas with large concentrations of one or more Southeast Asian ethnic group. California's Orange County is known worldwide as Little Saigon, the capital of Vietnamese Americans. Similarly, Long Beach, California, has the largest number of Khmer speakers outside of Cambodia. The public school system in California's Central Valley, including Fresno and Sacramento, has a higher percentage of Lao and Hmong students and teachers than anywhere else in the United States. This was not the outcome that the U.S. Office of Refugee Resettlement had anticipated. Earlier policy was designed to scatter the refugees across the country, from Pennsylvania to Florida, Arkansas and California. The refugees were expected by the resettlement office to quickly master basic English to enable them to fit into the lowest rung of the labor market, where cheap labor was most needed in the cities of their initial resettlement. With the beginning of the secondary refugee resettlement movement, however, these resilient refugees were attracted to other states and cities where the weather and climate were more like their home countries and where they were able to gather and establish their own vibrant economies and communities. Subsequent waves of refugees and immigrants continue to migrate to these areas where they find both opportunities and challenges in building their new lives. is distributed for non-commercial purposes only, and no alteration or transformation is made in the work. More details of this Creative Commons license are available at http://creativecommons.org/licenses/by-ncnd/2.5/. All other uses must be approved by the author(s) or JSAAEA. 
Southeast Asian American refugees and immigrants have affected every facet of American life, from education to health and politics. Many have gradually moved from their refugee status to naturalized citizenship, and some have now even become elected officials. Their children have straddled both sides of the American life, with some young Southeast Asian American adolescents labeled as delinquent, while others have been recognized as valedictorians. As an immigrant population, they have generally followed the acculturation stages of earlier immigrant groups. The first generation took minimumwage jobs and sacrificed for their children. Different ethnic groups found different economic niches in which they were soon recognized for their work ethic and determination.

Many members of generation 1.5 adapted quickly, adjusting to the new country, acquiring the language and excelling in school. They are grounded in their heritage culture and language and have been able to advance in mainstream society. Generation 2.0 and beyond are becoming so mainstreamed into the popular culture that they share more common values with their peers than with their heritage culture. Intergenerational conflicts are common among many Southeast Asian American families. Yet, the Southeast Asian American experience is unique and incomparable to that of earlier European immigrants or Latinos. The politics of their home countries and the relationship between the United States and their home countries occupies a big part of the adults' lives. Southeast Asians who emigrated as adults still refer to Cambodia, Laos, or Vietnam as "home" no matter how long they have lived in the United States. The second and third generations of Southeast Asian Americans balance the constant push of American culture with the persistent pull of their heritage cultures.

Despite the richness of the ethnic experiences and of the cultural, social, economic, and educational contributions and challenges that Southeast Asian Americans bring, there has been very little extensive or meaningful research done in these areas, and few literary works written on these subjects. While we do have a rich literature written in the native languages of Khmer, Lao, Hmong and Vietnamese by historical witness authors, these works are usually self-published in the form of memoirs and autobiographies, and are not widely disseminated. The majority of existing scholarly research studies have been carried-out by non-Southeast Asian Americans through an etic perspective - as outsiders looking in. This research has been valuable and informative, and we certainly encourage and welcome more of it; nonetheless, there is a strong need in the field for more research conducted by native Southeast Asian Americans scholars and researchers. Recognizing these needs, the Journal of Southeast Asian American Education \& Advancement (JSAAEA) has been established.

\section{The Journal of Southeast Asian American Education \& Advancement}

As an interdisciplinary scholarly journal, JSAAEA is designed to bring together research from experts - both native and non-native Southeast Asian Americans - in a wide range of fields, but written at a level accessible to all readers. The scope of the journal is broad, covering a wide range of issues related to education and advancement. Details on our interests in these areas are outlined below. While the focus of the journal is on Southeast 
Asian American refugee groups from Cambodia, Laos, and Vietnam, research related to any Southeast Asian Americans and communities is welcome and will be considered.

As an on-line journal, JSAAEA is free and easily accessible to interested readers throughout the world. Our decision to make JSAAEA an on-line journal is driven by our belief that academic research should be freely accessible to all members of the public, particularly those who may not have access to traditional (paper-based) journals tucked away on the dusty shelves of university libraries. Thus, our intended readership of the journal includes not only scholars and researchers, but also community leaders and members, educators, students, parents, and other professionals working in a wide range of fields affecting the lives of Southeast Asian Americans. Another advantage of publishing the journal on-line is that we will be able to publish articles as soon as they are ready, thus eliminating the long delays in the dissemination of research associated with traditional journals. Furthermore, contributors will have the potential of incorporating photographs and other forms of multimedia into their work which would be difficult or impossible in a paper-based journal.

Our Editorial Review Board consists of over 30 experts, all of whom hold doctoral degrees and actively conduct research on and/or work directly with Southeast Asian American communities; over half of the scholars on the review board are native Southeast Asian Americans. It addition, our Doctoral Student Review Board consists of ten up-and-coming young scholars who are native Southeast Asian Americans currently completing doctoral degrees. The members of our review boards are prepared to provide expert advice and give valuable feedback to those who submit their work for publication in the journal, and are especially committed to mentoring young scholars in the field.

In addition to articles reporting research and effective practice, the journal will also publish reviews of books (including children's literature) on Southeast Asian Americans and their communities. We view this section as an important resource to bring attention to the growing number of these books, and to provide a forum for their critical review. JSAAEA will also highlight creative works produced by Southeast Asian American youth. We believe these contributions are just as valuable as traditional research articles as they will provide important insights into issues of identity and the life experiences of Southeast Asian American youth.

JSAAEA is an official publication of the National Association for the Education and Advancement of Cambodian, Laotian, and Vietnamese Americans (NAFEA), with support from the Division of Bicultural-Bilingual Studies (BBL) and the College of Education and Human Development (COEHD) at the University of Texas, San Antonio (UTSA). (See Acknowledgements).

\section{The National Association for the Education and Advancement of Cambodian, Laotian and Vietnamese Americans (NAFEA)}

First established in 1978 by a group of former Vietnamese educators to provide support to school personnel, social service providers and community-based organizations, the organization was named NAVAE - The National Association of Vietnamese Americans in Education. In 1981, as more refugees from Cambodia and Laos arrived, the group united their efforts with Khmer and Lao educators and community leaders and 
transformed into a national organization to support educational, social and community development and advancement for all Southeast Asian refugees in their resettlement and acculturation process. Soon after, the organization adopted its current name and has since become an integral partner with many national and state Southeast Asian refugee resettlement organizations, including the Southeast Asian Resource Action Center (SEARAC), local school districts and institutes of higher education, and many mutual assistance associations (MAAs). NAFEA's goals and objectives continue to be inclusive of all Southeast Asian Americans in three primary areas: educational attainment, social/cultural foundations, and community/leadership development.

From 1998 to 2002, NAFEA worked closely with the Office of Bilingual Education and Minority Languages Affairs (OBEMLA). During this time period, NAFEA and OBEMLA co-organized and hosted a number of educational symposia, such as the National Forum on Asian and Pacific American Education, to bring together community leaders, teachers, graduate students and researchers. A research agenda was developed and proposed to the participants. These symposia brought attention to potential Southeast Asian American doctoral candidates and the need to do more research within Southeast Asian American communities on topics of importance to the leaders and members of these communities. Since then, the number of Southeast Asian American research studies by native scholars has slowly but steadily increased. NAFEA views the creation of the Journal of Southeast Asian American Education \& Advancement as a logical and timely next step to provide a legitimate venue for the dissemination of relevant research studies, as well as the creation of a network of concerned educators and researchers across the country. NAFEA recognizes the critical role of this journal in supporting its organizational goal of promoting Southeast Asian American educational attainment, sociocultural well-being, and community and leadership development.

\section{Overview of Journal Sections}

As described above, the journal will publish work in three broad areas: (1) Research and Practice, (2) Book Reviews, and (3) Creative Works.

\section{Research and Practice}

The Research and Practice section is for original research related to the education and advancement of Southeast Asian Americans and descriptions of effective research-based programs and practice within Southeast Asian American communities.

\section{Education}

Over one-third of Southeast Asian Americans are K-12 students, and growing numbers of these students are entering institutions of higher education. We are also seeing a slight increase in the number of Southeast Asian Americans electing to pursue teaching careers. Thus, we are greatly interested in research related to all aspects of early childhood education, K-12 education, higher education, and teacher education dealing with Southeast Asian American students. 
As many Southeast Asian American students in schools today are officially classified as Limited English Proficient (LEP) or English Language Learners (ELLs), there is a great need for research related to effective language education programs for these students. Thus we are greatly interested in research related to bilingual and heritage language programs in Southeast Asian languages such as Hmong, Khmer, Lao, and Vietnamese, and on ESL or other programs which are attempting to meet the needs of these students.

Related to issues of language teaching, there is a need for more research on linguistics, second language acquisition, and language learning in general, as they relate to Southeast Asian Americans acquiring/learning English, and/or developing or maintaining proficiencies in their native Southeast Asian American languages. Thus, we are greatly interested in research from the fields of linguistics, applied linguistics, and second language teaching and learning as they relate to Southeast Asian Americans.

\section{Advancement}

Southeast Asian Americans are integral parts of the communities in which they live. Outside the field of education, Southeast Asian Americans contribute to and are affected by a wide range of historical, social, cultural, economical, and political issues. We take a broad view of advancement to mean an investigation of how well Southeast Asian American individuals and communities as a whole are doing in America. Thus, in the area of advancement, we strongly encourage studies from a wide range of fieldssociology, psychology, history, intercultural communication, social work, health, economics, political science, and others-which can provide insights into the well-being of Southeast Asian Americans and communities, and into issues related to community development and leadership.

\section{Book Reviews}

In addition to publishing research articles, we are greatly interested in reviews of books pertaining to the topics of language, culture and cultural identity in Southeast Asian American communities. The book reviews are intended to cover a wide range of genres. We invite reviews of academic research texts, language learning texts, memoirs, other non-fiction or fiction books, and children's books.

\section{Creative and Literary Works}

Finally, outside of traditional academia there are a number of creative and literary works such as poetry, short stories, biographies and autobiographies, and short reflective essays which can provide immense insight into issues of the Southeast Asian American experience in ways that traditional research cannot. Thus, we strongly encourage these types of submissions, particularly from Southeast Asian American youth and young adults. 


\section{Reading and Contributing to the Journal}

We strongly encourage you to be active readers of this journal. You can register on the JSAAEA website as a reader. While you do not need to do this to access the journal's content, registering as a reader will allow you to be notified (via e-mail) any time a new article is published. We also plan to make it possible for registered readers to post comments on articles they read and to engage in dialogue with the authors and other readers regarding the issues addressed in the articles. Active dialogue on critical issues of common concern is essential for our SEA and American communities. To register as a reader, or to submit your own work, please visit the journal registration page at: http://jsaaea.coehd.utsa.edu/index.php/JSAAEA/user/register.

We also encourage you to contribute to the journal. We invite you to be a part of the larger community by contributing your ideas, knowledge, and research. We thank in advance those who contribute to JSAAEA for helping to promote better relations and understanding within and across our communities, for advancing knowledge and understanding of important issues affecting our Southeast Asian Americans communities and for contributing ideas toward collaboration and practical solutions.

Submission Guidelines are available on the journal website, and submissions may be either directly uploaded or sent via e-mail to the editors at jsaaea@lists.sis.utsa.edu. If you are conducting academic research, and/or have scholarly insight into important issues within the scope of the journal, we strongly encourage you to submit your work. If you are working in what you feel is an effective program serving Southeast Asian Americans and communities, we strongly encourage you to submit work describing the program and discussing the results. If you enjoy reading academic books or novels that fall within the scope of the journal, we strongly encourage you to write reviews of these books and to share your thoughts with others about them. If you are a teacher working with Southeast Asian American children and youth and use literature related to your students' native countries, cultures, and/or lives in the United States, we strongly encourage you to write a brief review of the book to let teachers, students and other members of the community know what the book is about, and what you think of it. If you do not have a book but would be interested in writing a review of one, just let us know and we may be able to send you one.

Finally, we ask you to please help spread the word about the Journal of Southeast Asian American Education \& Advancement to your interested colleagues and friends. This could be as simple as forwarding e-mails, posting announcements on listserves and websites, and using published articles in the classes you teach or programs for which you work.

Our vision is that JSAAEA will become the central location for all those interested in reading and contributing to the research knowledge base on Southeast Asian Americans and communities. This knowledge base will be an effective tool for all those who are working on improving the education and advancement of Southeast Asian Americans.

Wayne E. Wright, Ph.D.

University of Texas, San Antonio 
KimOanh Nguyen-Lam, Ph.D.

California State University, Long Beach

Chhany Sak-Humphry, Ph.D.

University of Hawaii

Leslie Turpin, Ph.D.

School for International Training

James Knaack

Editorial Assistant

University of Texas, San Antonio

\section{Acknowledgements}

We wish to thank Dr. Robert Milk, Division Director of Bicultural-Bilingual Studies (BBL) and Dr. Betty Merchant, Dean of the College of Education and Human Development (COEHD) at the University of Texas, San Antonio (UTSA) for providing support for the journal, including funding for graduate students who work as journal managers and editorial assistants, office space, computer equipment and other material supplies critical to the operation of the journal. We also wish to thank Jorge Garza, technology coordinator for the COEHD for his technical assistance and work to install the Open Journal Software and oversee the server space and security for JSAAEA, and Kip Hinton who provided early assistance with webpage design for the journal. We also wish to the thank Hiep Chu, President of the National Association for the Education and Advancement of Cambodian, Laotian, and Vietnamese Americans (NAFEA), and the members of the NAFEA Executive Board for their support and commitment to starting this journal. In addition, we are most grateful to the members of our Editorial Review Boards, all of whom have committed to volunteering their time and expertise to JSAAEA. Finally, we express our deep gratitude to the Public Knowledge Project for development and cost-free provision of the sophisticated Open Journal Systems software which has made this on-line journal possible. 

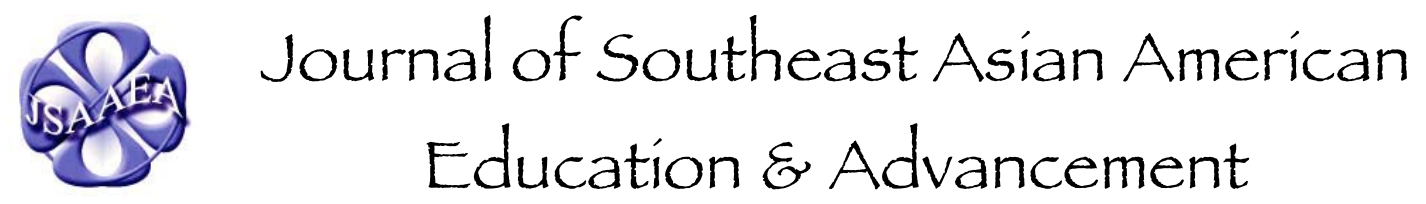

http://jsaaea.coehd.utsa.edu/index.php/JSAAEA
A peer-reviewed scholarly journal published by the National Association for the Education \& Advancement of Cambodian, Laotian, and Vietnamese Americans (NAFEA)

\author{
Editor \\ Dr. Wayne E. Wright \\ University of Texas, San Antonio \\ Associate Editors \\ Dr. Chhany Sak-Humphry \\ University of Hawaii \\ Dr. KimOanh Nguyen-Lam \\ California State University, Long Beach \\ Book Review Editor \\ Dr. Leslie Turpin \\ School for International Training \\ Creative Works Editor \\ Phouang Hamilton \\ Washington Office of Superintendent of Public Instruction \\ Special Advisor \\ Anne Frank \\ University of California, Irvine, Southeast Asian Archives \\ Editorial Assistant \\ James Knaack \\ University of Texas, San Antonio
}

Comments and questions for the editorial staff may be directed to jsaaea@ lists.sis.utsa.edu.

\title{
Editorial Review Board
}

\author{
Dr. Carl L. Bankston III \\ Tulane University \\ Dr. Pollie Bith-Melander \\ San Jose State University \\ Dr. Phala Chea \\ Lowell Public Schools \\ Dr. George Chigas \\ University of Massachusetts, Lowell \\ Dr. Changming Duan \\ University of Missouri, Kansas City
}

\author{
Dr. Sophal Ear \\ Syracuse University \\ Dr. Nancy H. Hornberger \\ University of Pennsylvania \\ Dr. Samlong Inthaly \\ Minneapolis Public Schools \\ Dr. Peter Nien-Chu Kiang \\ University of Massachusetts, Boston \\ Dr. Kevin K. Kumashiro \\ University of Illinois, Chicago
}


Wright et al.: Editors' Introduction - Fulfilling a Critical Need: The Journal o

\author{
Dr. Stacey Lee \\ University of Wisconsin, Madison \\ Dr. David Chanpannha Ley \\ Montgomery County Public Schools \\ Dr. Sue Needham \\ California State University, Dominguez Hills \\ Dr. Bic Ngo \\ University of Wisconsin-Madison \\ Dr. Max Niedzwiecki \\ Independent Scholar \\ Dr. Leakhena Nou \\ California State University, Long Beach \\ Dr. Clara Park \\ California State University, Northridge \\ Dr. Mark Pfeifer \\ Texas A\&M University, Corpus Christi \\ Dr. Loan T. Phan \\ University of New Hampshire \\ Dr. Bounlieng Phommasouvanh \\ Minnesota Department of Education \\ Dr. Karen Quintiliani \\ California State University, Long Beach
}

\author{
Dr. Kalyani Rai \\ University of Wisconsin, Milwaukee \\ Dr. Fay Shin \\ California State University, Long Beach \\ Dr. Nancy J. Smith-Hefner \\ Boston University \\ Dr. Yer J. Thao \\ Portland State University \\ Dr. Myluong Tran \\ San Diego State University \\ Dr. Khatharya Um \\ University of California, Berkeley \\ Dr. Linda Trinh Vo \\ University of California, Irvine \\ Dr. Terrence G. Wiley \\ Arizona State University \\ Dr. Zha Blong Xiong \\ University of Minnesota \\ Dr. Kou Yang \\ California State University, Stanislaus
}

\title{
Doctoral Student \\ Editorial Review Board
}

\author{
Keo Chea \\ University of Pennsylvania \\ Vichet Chhuon \\ University of California, Santa Barbara \\ Loan Dao \\ University of California, Berkeley \\ Annie BichLoan Duong \\ San Joaquin County Office of Education \\ Ha Lam \\ Arizona State University \\ Vanna Som \\ Harvard University
}

\author{
Giang Tang \\ University of Minnesota \\ Layheng Ting \\ State University of New York, Albany \\ Loan Tran \\ University of California, Santa Barbara \\ Phitsamay Sychitkokhong Uy \\ Harvard University \\ Yang Sao Xiong
University of California, Los Angeles \\ Yang Sao Xiong
University of California, Los Angeles \\ Yang Sao Xiong
University of California, Los Angeles
}

